\title{
Mulemba
}

Revista Angolana de Ciências Sociais

5 (10) | 2015

Angola 40 anos de independência: memória, identidades, cidadania e desenvolvimento

\section{Luanda. Estudo de Geografia Urbana, a reedição de uma obra clássica que chega em boa hora}

\section{Luiekakio Afonso}

\author{
(2) OpenEdition \\ Journals \\ Edição electrónica \\ URL: https://journals.openedition.org/mulemba/2143 \\ DOI: $10.4000 /$ mulemba. 2143 \\ ISSN: 2520-0305 \\ Editora \\ Edições Pedago \\ Edição impressa \\ Data de publição: 1 novembro 2015 \\ Paginação: 793-807 \\ ISSN: 2182-6471 \\ Refêrencia eletrónica \\ Luiekakio Afonso, «Luanda. Estudo de Geografia Urbana, a reedição de uma obra clássica que chega em \\ boa hora», Mulemba [Online], 5 (10) | 2015, posto online no dia 12 outubro 2018, consultado o 21 \\ setembro 2021. URL: http://journals.openedition.org/mulemba/2143; DOI: https://doi.org/10.4000/ \\ mulemba.2143
}




\section{Luanda. Estudo de Geografia Urba- na, a reedição de uma obra clássica que chega em boa hora*}

\section{Luiekakio Afonso**}

Quando me foi oferecido um exemplar da obra clássica Luanda. Estudo de Geografia Urbana, do Professor Ilídio do Amaral, pelo Coordenador na colecção «Ciências Sociais e Humanas» da Editorial Kilombelombe, propondo-me que fizesse a sua apresentação pública, senti-me realmente honrado e isso por variadas razões: primeiro, porque não se trata apenas de um livro de Geografia, mais concretamente de Geografia Urbana, mas sim de uma obra extraordinária de ciência que se tornou referência para analisar qualquer realidade urbana a escala nacional ou mesmo global; em segundo lugar, porque se trata de uma obra escrita há mais de 47 anos, por um dos mais proeminentes geógrafos, oriundo de um dos países de língua oficial portuguesa, mais exactamente, nascido em Angola, no então «distrito de Luanda», em Setembro de 1926, podendo, em termos de prestígio, o seu nome ser posicionado ao lado de eminentes

* Texto da apresentação pública da obra do Professor Ilídio do Amaral, Luanda. Estudo de Geografia Urbana (Luanda, Kilombelombe, 2015, 212p. [ «Ciências Humanas e Sociais - Série Geografia Humana e Demografia»; 1]), efectuada no anfiteatro principal da Faculdade de Ciências Sociais (FCs) da Universidade Agostinho Neto (UAN), no dia 29 de Outubro de 2015, por ocasião do $v$ Colóquio de Ciências Sociais: Angola 40 Anos de Independência: Memória, Identidades, Cidadania e Desenvolvimento, organizado pela FCS-UAN em Luanda nos dias 29 e 30 de Outubro de 2015.

** Professor Associado, Vice-Decano para Área Académica e Chefe do Departamento de Geodemografia da FCS-UAN. 
geógrafos à escala mundial, tais como Milton Santos e Aziz Ab'Saber (do Brasil), ou Orlando Ribeiro e Jorge Manuel Barbosa Gaspar (de Portugal); em terceiro lugar, porque enquanto estudante do programa de doutoramento «Território e Sociedade», no Departamento de Geografia Humana da Faculdade de Geografia e História da Universidade Complutense de Madrid (1998-2004), procurei adquirir essa obra tanto em Portugal quanto em Espanha ou em França, sem nunca o ter conseguido, pois a mesma não aparecia em lado nenhum porque estava esgotada fazia décadas. Não tendo conseguido adquiri-la, tive que me contentar com o estudo de outros excelentes materiais do mesmo autor, tais como como os textos Luanda e os seus Muceques: problemas de Geografía Urbana (datado de 1983 e editado pela Finisterra) ou $A$ propósito das cidades do terceiro Mundo: contribuições geográficas (datado de 1988 e publicado pela revista lisboeta Garcia de Orta, na série de Geografía, vol. 13; n. ${ }^{\text {os }} 1$ e 2), só para citar apenas alguns dos seus mais importantes títulos sobre a cidade capital do nosso país.

Receber, pois, esta excelente obra agora reeditada foi, portanto, motivo mais do que suficiente para aceitar o convite que me havia sido formulado para apresentá-la aqui, hoje e agora, nesta nossa casa do saber, e aproveitar desde já a oportunidade para felicitar a Editorial Kilombelombe, primeiro, pelo empenho em reeditar este livro excepcional, e, em segundo lugar, pela qualidade editorial da mesma; e por fim, felicitar igualmente o Banco de Poupança e Crédito (BPC), pela concessão da subvenção, que, uma vez mais, contribuiu para que mais uma obra fosse editada e, especificamente, para que esta obra pudesse ser divulgada em Angola e pudesse ser colocada na mão dos nossos estudantes. É um feito que, em meu modesto entendimento, deve ser anunciado e amplamente divulgado.

A obra em apresentação foi publicada em 1968 e é considerada a primeira de carácter científico sobre Luanda (p. XIV) ${ }^{\mathbf{1}}$ e, tida, de acordo com a nota de abertura assinada pela Editorial Kilombelombe, como «um marco académico e político na esteira do ordenamento do território». Esta edição fac-similada² de 2015, começa

1 O trabalho de investigação sobre o terreno, efectuado entre 1963 e 1965, assim como a execução e a publicação do livro, só foi possível porque estava inscrito no âmbito dos programas da Missão de Geografia Física e Humana do Ultramar, criada pela Junta de Investigações do Ultramar (JIU).

2 Um fac-símile (ou edição fac-similar) é uma edição nova (frequentemente de um livro antigo), que apresenta uma reprodução exacta da edição original, incluindo fontes de letras, escala, ilustrações, diagramas e paginação. 
com um pequeno e brilhante texto adicional assinado em Janeiro de 2015 pelo próprio autor, intitulado «Luanda: cidade de mais de quatro séculos, de capital de província ultramarina à capital de estado independente» e que serve para abrir esta nova edição, para depois penetrar em matérias sobre Luanda que, entre 1963-1965 - período de levantamento da informação -, o professor Ilídio do Amaral observou e descreveu minuciosamente.

Neste livro, estão assim assentes as bases da Geografia Urbana de Luanda e de um modelo de estudo Geodemográfico, assim como, da própria História da cidade de Luanda.

O ponto de partida que me permitiu tecer algumas considerações sobre esta obra, foi interrogar-me: «quem é, academicamente falando, realmente Ilídio do Amaral, e que obra é esta, Luanda. Estudo de Geografia Urbana?»

Apercebi-me, desde logo, que não me seria fácil apresentar hoje, em pleno ano de 2015, alguém que nasceu em 1926, que conta já com seus 89 anos de idade e ainda está vivo. Da leitura feita, fiquei a saber qual o seu nome completo: Ilídio de Melo Peres do Amaral, sendo mais conhecido nas lides académicas, simplesmente por Ilídio do Amaral, Geógrafo e Professor Catedrático Jubilado da Universidade de Lisboa, da qual foi Vice-Reitor e Reitor entre 1975-1980. Foi também, de acordo com Adelino Torres, outro vulto do conhecimento sobre múltiplas questões e dentre as quais se inclui Angola, Reitor da Universidade Internacional (2007). ${ }^{3}$ Licenciou-se em Geografia em 1956 na Faculdade de Letras da Universidade de Lisboa, onde apresentou a sua monografia, intitulada justamente São Paulo de Assunção de Luanda. É Académico Emérito da Academia de Ciências de Lisboa, Académico de Mérito da Academia Portuguesa de História, Académico Correspondente da Academia Internacional da Cultura Portuguesa e Sócio da Sociedade de Geografia de Lisboa.

A sua bibliografia científica reúne, no momento actual, 482 títulos, entre livros, artigos e comunicações em várias línguas; notas e recensões, prefácios de obras de outros autores, relatórios e pareceres, programas de investigação científica e desenvolvimento, etc.

3 Disponível em <http://www.adelinotorres.com/autores/Professor\%20Ilidio\%20do\%20Amaral_CV.pdf> (Professor Doutor Ilídio do Amaral «1926-», Notas Curriculares), consultada em Outubro de 2015. 
Alguns dos seus livros foram premiados, sendo os casos de Santiago de Cabo Verde. A terra e os homens (1964); Luanda. Estudo de Geografia Urbana (1968); O reino do Congo, os Mbundu (ou Ambundus), o reino dos «Ngola» (ou de Angola) e a presença portuguesa de fins do século XV a meados do século XVI (1996).

Como escreveu Joaquim Bosque Maurel, ${ }^{4}$ um renomado géografo espanhol, num dos seus trabalhos sobre Crescimento demográfico, revolução urbana e novas tecnologias, "a história da Humanidade é, na sua essência, a história da ocupação e do uso, as vezes até abusivo e destrutivo da Terra. Nessa história, a cidade, uma das grandes criações da sociedade humana, tem sido e é protagonista excepcional. E como tal, a cidade, um facto social e histórico, caracteriza-se pela sua situação de mudanças permanentes. Tanto em função da promoção social como consequência das transformações tecnológicas de cada sociedade e em cada um dos seus momentos históricos. Uma mudança que, em certos casos e nalgumas ocasiões, poderia qualificar-se de revolucionária». É nesse contexto e perspectiva, que podemos enquadrar esta excepcional obra.

Luanda. Estudo de Geografia Urbana, é um livro que, segundo o seu autor, resultou de um trabalho aturado de levantamentos in loco de aspectos físicos e humanos, de consultas documentais e de inquéritos e foi galardoado com dois prémios e numerosas menções honrosas. É uma obra científica que pode interessar a especialistas, tanto da área das Ciências Sociais e Humanas, quanto das engenharias, arquitectura, e gestão administrativa do Estado, sobretudo em labores do ordenamento do território, planeamento e desenvolvimento urbano. A obra contém 212 páginas impregnadas de quadros estatísticos, gráficos e fotografias, e, principalmente, de numerosas e extraordinárias plantas e mapas, que representam a evolução territorial de Luanda e os usos do solo. Para além das duas notas de abertura (uma assinada pela Editorial Kilombelombe e outra pelo próprio autor), do prefácio original (pp. 9-10), da introdução (pp. 11-14), dos elementos bibliográficos (pp. 183-192), da conclusão (pp. 167-181) e dos anexos, o livro está estruturado em cinco (5) capítulos: o primeiro, que refere a «Apresentação da cidade de Luanda» (pp. 15-38), o segundo que versa sobre a «Génese e evolução de

4 Bosque Maurel (s.d.), Crescimento demográfico, revolução urbana e novas tecnologias, Madrid (material docente). 
Luanda» (pp. 39-68), o terceiro sobre «Luanda e a sua população» (pp. 69-106), o quarto que trata das «Actividades urbanas» (pp. 107-134) e o quinto e último, que analisa a questão da «Expansão urbana e os seus problemas» (pp. 135-165).

Seria imprudente da minha parte, começar por apresentar a obra tal como foi publicada em 1968, sem contudo, fazer uma referência, embora sumária, do pequeno texto de abertura deste livro, que contém 8 páginas (cf. XIII-Xx). Nessas páginas, o professor Ilídio do Amaral, faz-nos saber da sua paixão académica pela cidade de Luanda e oferece-nos uma rica síntese histórica da evolução da cidade, desde que deixou de ser em 1975 a capital da Província Ultramarina de Angola para adquirir o estatuto de capital do Estado Independente, até a etapa actual. Para o Ilustre Professor, tudo mudou na cidade que hoje tem cerca de 439 anos de existência, a mais antiga da África Subsahariana. Data de meados do século xx que se começou a registar a explosão urbana de Luanda. Se em 1960, as duas partes da cidade «a cidade do asfalto mais os musseques» contavam apenas com 224.540 habitantes, e, dez anos depois, no Censo de 1970, com 561.145 habitantes, já em 2014, os resultados preliminares do Recenseamento Geral da População e Habitação (RGPH) mostram bem a explosão demográfica da cidade, que passou a contar com 6.542.944 habitantes. Se fizermos um pequeno exercício de estatística demográfica, teríamos a seguinte situação: uma taxa de crescimento populacional da ordem de $5,58 \%$, o que significa dizer, que em 44 anos (desde 1970), a população de Luanda aumentou 12 vezes mais, o que pressupõe, por outro lado, que mantendo constante no tempo essa taxa de crescimento, em apenas 12,5 anos, o valor observado em 2014 poderá duplicar-se. A distribuição da população pelos sete municípios que hoje ordenam a cidade, é extraordinariamente desigual, principalmente nos âmbitos de residência rural-urbano, pois, dos 6,5 milhões de habitantes, apenas cerca de 166 mil pertencem à zona rural e o restante, ao conjunto de 4 municípios (Luanda, Cazenga, Viana e Belas) que conformam, segundo o Professor Ilídio do Amaral, a «Grande Luanda».

A macrocefalia de Luanda é dada também, por um lado, pela expansão urbana e, por outro lado, pela excessiva concentração de serviços públicos e de sedes de empresas nacionais e multinacionais de diversos tipos no núcleo antigo ou baixa da cidade.

No que toca a geomorfologia, o autor chama a atenção sobre as alterações dos dois arcos de vulnerabilidade e risco da cidade de 
Luanda - o das restingas e o das escarpas abarrocadas - que, de certo modo, condicionam o tecido urbano da cidade. Quanto ao cordão de areias da Ilha de Luanda, é preciso não esquecer que ele protege a baía das ondulações oceânicas e dos seus efeitos destruidores em época de «calemas». Para o professor Ilídio do Amaral, a Ilha de Luanda merecia ser respeitada como nicho ecológico e histórico.

Em Luanda, como em muitas outras cidades de África Subsahariana, o espaço urbano é visivelmente distribuído em duas partes: uma, a «central», que o professor Luís Filipe Nery de Sousa Colaço, num dos seus trabalhos classificou de «Centro Moderno» (neste caso, o actual Município de Luanda), dotado de estruturas urbanísticas regulares e de actividades económicas regulamentadas; e outra, a «periferia» (os nossos galopantes musseques) mais densamente povoada e desprovidos de estruturas urbanísticas e onde predominam, portanto, as actividades informais.

O Professor Ilídio do Amaral, caracteriza hoje Luanda, como estando numa fase explosiva de «revolução urbana», pois se observam grandes alterações na parte central da cidade, testemunhado pelo adensamento dos edifícios de grande desenvolvimento vertical e múltiplas funcionalidades, e pela profusão de modelos arquitectónicos que substituem as construções mais antigas, resultando disto, grandes contrastes. «Essa metamorfose repentina e violenta - penso eu - tem levado a morte paulatina da história da cidade de Luanda, tal como o podemos constatar, muito recentemente, com um grupo de estudantes de Geodemografia, no trabalho de campo II, dedicado ao estudo da paisagem cultural de Luanda». Mas também, noutras partes da cidade, incluindo os musseques, as alterações têm sido profundas. A proliferação de «condomínios murados», escondendo a sua beleza arquitectónica, pois muitos deles, de acordo com o professor, «são de luxo, símbolos de riqueza», os «programas de requalificação dos musseques», e as «cidades 798 satélites».

No penúltimo parágrafo deste texto breve, o professor escreveu o que se segue: «Luanda, é hoje uma megacidade, fragmentada, prismática, caleidoscópica e cosmopolita, com difíceis problemas de gestão urbana, entre os quais se incluem os da racionalidade do seu planeamento, os da garantia de serviços básicos como os da habitação, de assistência social, dos transportes públicos, dos fornecimentos regulares de água e energia eléctrica, etc.» (p. XIX). Continuando nesta mesma ordem de ideias, observa judiciosamente: 
«A par de megacidade, [Luanda] adquiriu a categoria de cidade global, centro estratégico de um País exportador de riquezas naturais, minerais (lugares cimeiros como produtor de petróleo e de diamantes), vegetais (as madeiras e produtos agrários). É parte de redes globais de geometrias variadas que caracterizam o mundo actual em fase acelerada de globalização graças aos instrumentos cada vez mais sofisticados que potencializam as actividades de negócios internacionais, a simultaneidade do intercâmbio de informações, os compromissos políticos mundiais» (pp. XIX-xx).

A título de recomendação, o professor lembra que é «urgente uma revisão do modo de ver e sentir essas cidades», referindo-se, sobretudo às cidades da África Subsahariana, e na qual se inclui Luanda. Para dar sentido a essa sua recomendação o professor Ilídio do Amaral recorreu à constatação feita por duas autoras africanas, especialistas de planeamento urbano e regional, a sul-africana Vanessa Waston e a nigeriana Babatunde Agbola, que na obra Who will plan Africa's cities?, datada de 2013, escreveram: «As cidades africanas estão a crescer e a mudar, rapidamente, sem planeamento apropriado. Com o decorrer do tempo correrão o risco de se tornarem caóticas, ineficientes e insustentáveis. Em muitos casos o planeamento data da era colonial, mal equipado para lidar com os problemas urbanos contemporâneos». Eis aqui a visão do autor deste livro acerca da Luanda de hoje.

Vejamos agora um pouco sobre a cidade de Luanda que este observou até 1968, e que levou à publicação desta obra. Na sua introdução, no primeiro capítulo ( «Apresentação da cidade de Luanda») e no segundo ( «Génese e evolução de Luanda»), o professor Ilídio do Amaral começa por apresentar-nos a situação geográfica e a evolução de São Paulo de Assunção de Luanda, a capital da província ultramarina portuguesa de Angola, situada numa terra semi-árida e quente sob a uma baía de águas calmas a cerca de $8^{\circ} 48^{\prime}$ de latitude sul e $13^{\circ} 13^{\prime}$ de longitude leste, entre os rios Bengo e Kwanza. É um lugar, no dizer do professor, com um ambiente natural de resultados negativos: clima pouco agradável, fraqueza de reservas de água e de riquezas do subsolo, pobreza dos solos, impróprios para uma actividade agrícola proveitosa e lucrativa, assim como, escassez de vegetação. Não obstante tais factores aparentemente negativos, o sítio foi escolhido pela sua posição alcandorada no interior de uma baía de defesa fácil, na época em que se temiam os ataques dos indígenas do interior e dos inimigos estrangeiros. 
A cidade foi fundada em princípios de 1576 por Paulo Dias de Novais, em obediência às directrizes de um plano geral de ocupação e colonização de «terras novas», subscritos pelo monarca luso. Nomeado seu conquistador, primeiro governador e capitão-general (através da carta de doação de 19 de Setembro de 1571), partiu de Lisboa em 23 de Setembro de 1574 comandando uma armada (com 700 homens, dos quais metade eram soldados e quatro religiosos da Companhia de Jesus, que fundariam a Missão de Angola), chegou no dia 11 de Fevereiro do ano seguinte à vista da Barra do Cuanza (onde já estivera pela primeira vez em Maio de 1560), navegou mais para o norte e entrou, pela Barra da Corimba. Nesta Ilha, feudo do rei do Congo, que dela retirava o «zimbo» (búzio pequeníssimo que servia como dinheiro), viviam «cerca de 3 mil pretos em seis ou sete povoações, na sua maioria pescadores, e 40 portugueses fugidos do Congo».

Deste ponto, portanto, Luanda, partiu-se para a exploração e a conquista do interior, marcada, na sua primeira fase, pela procura das minas de prata, que se pensava existirem na região de Cambambe. Conquistada a área em 1604, e o desmoronamento do sonho, pois não existiam as ditas minas de prata, passou-se a exploração em grande escala, do negócio de escravos, que já era exercido antes da chegada de Paulo Dias de Novais, pelos contratadores de São Tomé. Nesse segundo projecto de conquista de Angola, os escravos passam a sair em grandes quantidades para o Brasil, onde eram necessários para os engenhos de açúcar.

O século XvI foi de guerra na Europa e de guerra marítima e colonial. Em Agosto de 1641 a cidade foi ocupada pelos Holandeses até 15 de Agosto de 1648, data da sua libertação por uma armada organizada no Brasil e comandada por Salvador Correia de Sá e Benevides, governador das capitanias do Sul do Brasil.

De acordo com o professor Ilídio do Amaral, a concentração de 800 todos os esforços no tráfico de escravos para o Brasil e o uso de Angola como depósito de penal para degredados da Metrópole e do Brasil, foram os dois principais factores que entravaram a evolução de Angola. Calcula-se que só entre 1648 e 1769, Angola tenha sido exaurida ou esvaziada de cerca de 2.075.700 habitantes, que foram convertidos, portanto, em escravos e desse total, 462.000 teriam saído de Luanda. Por volta de 1730, havia em Luanda apenas 150 brancos. Nesse ano, após 40 dias de chuvas e inundações, quase todos os homens tinham morrido ou se encontravam muito doentes, 
tendo sido atacados por infecções gerais, varíola e escorbuto, conhecido como «o mal de Luanda».

Entre 1817-1818, a população de Luanda era estimada em 3.199 habitantes, dos quais, 355 Brancos, 472 Pardos (desses, 420 livres e 52 escravos) e 2.372 Pretos (desses, 813 livres e 1.559 escravos). Já em meados de 1845 (27 anos depois) a população era de 5.605 habitantes, dos quais, 1.601 Brancos, 491 Pardos (desses, 475 livres e 16 escravos) e 3.513 Pretos (desses, 780 livres e 2.733 escravos).

Até 1818 , a economia da cidade baseava-se sobretudo em três produtos importantes: escravos, marfim e cera.

Até ao século XIx, Luanda ficou reduzida a «acampamento» de população flutuante, que aí acorria para enriquecer com o tráfico de escravos para o Brasil (principalmente para Salvador de Bahia), ou era habitava por imposição do Estado (funcionários públicos e degredados), em regra homens, que se cruzavam com as mulheres da terra. O crescimento de Luanda foi tão lento que, no decorrer de três séculos, toda a área urbana se manteve dentro dos limites definidos pela fortaleza se São Miguel, Ermida de São José (onde hoje está o Hospital Central), Convento de Nossa Senhora do Carmo, Ermida da Nazaré e a praia da baía. Por exemplo, em 1600, quando Salvador da Bahia (Brasil) já tinha uma população de cerca de 8 mil habitantes, a de Luanda não ultrapassava a quarta parte e, em 1950, enquanto a da Bahia era de 389.422 habitantes, a de Luanda era de apenas 141.647.

Desde a sua fundação no cimo do morro de São Miguel (actual Museu Nacional das Forças Armadas) até a altura do levantamento do estudo deste livro (1963-1965), houve uma evolução significativa de Luanda em termos de morfologia urbana (ver mapa 1, p. 213). Inicialmente, a povoação foi crescendo, na parte alta, com uma planta simples, linear. Dadas as condições topográficas, é fácil perceber a disposição da cidade em dois planos ou cidades, tal como em Salvador da Bahia: a «Cidade Alta», onde ficavam o palácio do governador (hoje conserva a sua importância histórica, como centro do poder político - Palácio Presidencial, Assembleia Nacional, ministérios Justiça, da Defesa Nacional) e as moradias da aristocracia ou nobreza; a «Cidade Baixa», de actividade comercial e portuária, com os seus armazéns e quintais para escravos. Entre as duas cidades, as ligações estabeleciam-se através de caminhos e calçadas íngremes ou abruptas.

Depois da Segunda Guerra Mundial, sob os efeitos da abastança dos lucros da exportação de café, do investimento de capitais na 
construção civil e na indústria, do aumento da imigração europeia e maior fluxo de gente do interior da província, a velha cidade modificou-se profundamente. De uma cidade bem portuguesa, pela presença dos seus palácios e sobrados, das suas igrejas barrocas, das suas casas tradicionais, pelos seus bairros antigos de tradições populares, pela organização do seu plano geral, hoje já pouco ou nada resta. Tudo tem sido demolido (parece-me que essa febre das demolições não é de hoje nesta cidade) e, sobre os terrenos limpos, erguem-se os blocos altos de ferro e cimento, tão iguais e insípidos como quaisquer outros, não importa em que cidade moderna do globo. Belas obras de arquitectura ultramarina dos séculos XVII e XVIII, de expressão bem portuguesa, ainda que consideradas monumentos classificados, têm desaparecido sob a fúria de renovação destas duas escassas dezenas de anos, tal como já constatara o arquitecto Fernando Batalha em 1963, num dos seus trabalhos Em defesa do património histórico e tradicional de Angola: «inutilizando a obra multissecular de muitas gerações».

Em síntese, durante esse período (décadas de 1950 e 1960), a cidade foi perdendo a originalidade que tinha, sacrificada à ânsia de renovação e de modernização constantes. Parece-nos que essa realidade narrada naquelas décadas, é a que Luanda está a viver de 2005 a esta data, sufocando a parte antiga da cidade com os que o professor classificou de «insípidos» os «imparáveis arranha-céus» de Luanda e a requalificação «algo desmedida» da majestosa Avenida Marginal.

O espaço de Luanda carece de uma rigorosa estruturação em áreas urbanas individualizadas por tipos especiais de actividades. As actividades urbanas aparecem misturadas: na mesma rua coexistem edifícios de diferentes idades e aspectos desiguais; estabelecimentos comerciais e industriais, etc. Em cada imóvel moderno, dos de muitos andares, a complexidade ainda é maior, porque rapidamente se pode passar do sector comercial para o dos serviços, deste para habitação ou para escola.

Já no capítulo III, «Luanda e a sua população» e no capítulo IV, «Actividades urbanas», o professor Ilídio do Amaral aborda os aspectos gerais da evolução, estrutura e actividades económicas da população de Luanda, ao mesmo tempo que analisa em pormenor os aspectos relacionados com a estrutura comercial e dos serviços, o equipamento industrial, o movimento portuário, as funções: social e cultural, entre outras. 
Se até 1845 a taxa de crescimento da população de Luanda era inferior a $1 \%$ (o,8\% em 1845), um crescimento relativamente moderado, portanto; não se pode dizer o mesmo a partir de 1930, quando começam a observa-se taxas de crescimento acima de $2 \%$, chegando a taxas da ordem de 8,4\% no período 1940-1950 (P1940 = 61.028 hab. e P1950 = 141.647 hab.), notando-se uma clara duplicação da população nesta década, facto que se pode associar, não só ao crescimento natural dos seus habitantes (sobretudo os não brancos, mas, principalmente, pela chegada maciça de «imigrantes» portugueses à colónia). Em 1960, a população de Luanda era de 224.540 habitantes (Censo 1960). Até essa data, Luanda situava-se distante como maior aglomeração populacional de Angola, com apenas 4,6\% da população total (a população de Angola em 1960 era de 4.830.449 habitantes), concentrando actualmente $27 \%$ da população total do país.

No entanto, vale ressaltar que a evolução conturbada de Angola e de Luanda em particular (tráfico de escravos, o contrato, ponto de passagem para outras regiões), fez com que se observassem flutuações significativas no seu processo de crescimento.

A distribuição da população por grupos somáticos era a seguinte: 24,7\% Brancos; 6,1\% Mestiços e 69,2\% Pretos. Mesmo naquela época (1960), a pirâmide etária era representativa da população jovem. Para o conjunto da população (Brancos, Mestiços e Pretos), cerca de $80 \%$ tinha idades inferiores a 35 anos. A relação de masculinidade era de 136 homens por cada 100 mulheres (actualmente é de 96 homens por cada 100 mulheres). Uma das principais razões era a existência de uma maior percentagem de imigrantes do sexo masculino: $85,8 \%$ da população professava a religião católica, 10,8\% protestantes e 3,4\% era de outras religiões.

A distribuição espacial da população era também bastante desigual, pois estava subdividida em três principais bairros administrativos: $1^{\circ}$ bairro administrativo, de brancos (Baixa da cidade): 42.498 habitantes; $2^{\circ}$ bairro administrativo, de mestiços (Vila Alice, Vila Clotilde, Bairro do Café, etc.): 140.633 habitantes; e $3 .^{\circ}$ bairro administrativo, de pretos (Catambor e Prenda, sobretudo): 41.409 habitantes. Importa aqui referir, que tanto no $2 .^{\circ}$ como no $3 .^{\circ}$ bairros administrativos, a população negra era maioritária, não sucedendo o mesmo no $1^{\mathrm{o}}$ bairro administrativo, em que 26.171 eram brancos; 11.4017, pretos; 4.883, mestiços e 37, de outros.

Alguns aspectos socioeconómicos da população destacados pelo Professor Ilídio do Amaral, prendem-se com a evolução bastante 
desigual na cidade, entre a sociedade africana e sociedade branca. Na cidade urbanizada, de predominância branca, encontramos actividades economicamente rentáveis e variados (comércio, espaços de diversões, administração, indústria, finanças, etc.) e nas extensas aglomerações tipicamente africanas, os musseques, habitam grupos desfavorecidos com níveis de vida muito baixos e com ocupações menos rentáveis (criados de mesas em restaurantes e cafés, criadas domésticas e lavadeiras, porteiros, horticultores e vendedores nos mercados, cauteleiros e vendedores ambulantes, etc.). Portanto, até a data de referência, não havia ainda interdições profundas do tipo racial, pois todos os grupos humanos (brancos, mestiços e pretos) poderiam habitar, indistintamente, qualquer área da cidade; a separação era, sobretudo, do tipo económico e social.

A população economicamente activa (cerca de $48 \%$ da população total em 1960), estava ocupada nas seguintes actividades: Serviços pessoais e outros (56,3\% da PEA); Actividades comerciais (23,7\%); Indústria manufactureira (7,6\%); Serviços públicos (6,9\%); Agricultura e Silvicultura (4,0\%) e Pesca e Indústria extractiva (0,4\% da PEA).

O comércio e prestação de serviços, incluindo as actividades portuárias, têm sido as funções mais antigas e, ainda hoje, de maior importância em Luanda. Em 1966 existia em Luanda 231 estabelecimentos comerciais, espalhados por toda parte da cidade, mas com maior realce para a Cidade Baixa (estabelecimentos de modas, ourivesarias e relojoarias, armazéns de móveis de luxo, de louças e artigos decorativos, etc.) e, neles estavam ocupados, 327 de pessoal especializado e 280 não especializado.

Até 1965, os tipos de indústrias predominantes eram: têxteis, vestuário e calçado (por exemplo: Textang-Textáfrica); alimentação e bebidas (exemplo: Cuca, Nocal, Sovan - Sociedade vinícola franco-angolana); química e similares (exemplo: Petrangol); cons804 trução civil e mobiliário; mecânica e metalurgias; tabaco, etc., etc.

A situação geográfica da cidade, permitiu a criação do porto de Luanda que desempenhou, e continua a desempenhar ainda hoje, um papel importante nas relações económicas entre a cidade e o resto da província ultramarina de Angola, estando conectado por uma rede de estradas e por uma linha férrea de penetração.

No mapa 1, os leitores que adquirirem esta obra, encontrarão uma extraordinária planta sinóptica das formas de ocupação e/ou utilização do solo na cidade de Luanda (instrumento importantíssimo de 
Ordenamento e Planeamento Urbano de Luanda). Nesta planta, estão assinaladas as funções dos diferentes espaços, social, cultural e outras, isto é, desde a função residencial, comercial, industrial, serviços diversos, agremiações culturais e desportivas, etc.

$\mathrm{O}$ último capítulo, o quinto, foi reservada à questão da «Expansão urbana e os seus problemas", no qual o professor analisa em profundidade e pormenor questões relevantes do dinamismo do crescimento urbano, a área de maior centralização de actividades económicas e o seu foco, e finalmente, os musseques situados na periferia da cidade de Luanda.

De acordo com professor Ilídio do Amaral, «ao fim de cerca de quatro séculos, o crescimento de Luanda tomou, nos últimos vinte anos aspectos de verdadeira "explosão urbana"». Em termos de população, o seu aumento relativo entre 1940 a 1960 foi de cerca de $270 \%$, que resultou principalmente da imigração maciça, vinda sobretudo do interior da província, atraída pela expansão das actividades urbanas. Para termos uma ideia sobre essa expansão, o professor diz-nos que até 1940, os «musseques» ainda estavam nas Ingombotas, no Maculusso, no Bungo, portanto, a menos de $1 \mathrm{~km}$ do centro da cidade, numa altura em que se mandou elaborar o primeiro Plano de Urbanização de Luanda, a fim de se começar a organizar e a dirigir a implantação dos elementos urbanos, evitando-se assim a multiplicação dos erros resultantes da falta de um plano, que a aplicação de modelos europeus, mal adaptados às condições da cidade, tentava substituir.

Nesse processo de Planeamento Urbano e de Requalificação de alguns espaços, afectou também algumas partes do Porto, tendo sido regularizada a praia da baía, e, sobre ela, se construiu a Avenida Marginal, assim como os edifícios altos, a exemplo do Banco Comercial de Angola (BCA), uma torre de 26 andares, e que alberga actualmente o BPC - Banco de Poupança e Crédito, a entidade bancária que subvencionou muito justamente a reedição desta obra.

Ainda acerca da expansão das actividades urbanas, o professor Ilídio do Amaral escreveu o seguinte: «[...] o surto das actividades urbanas, iniciado por volta de 1950, tem-se mantido num ritmo acelerado, apenas afrouxado nos anos de 1957 a 1961, período de insegurança e apreensão, marcado pela descida das cotações dos produtos agrícolas de exportação rendosa, como o café, sisal, algodão, e pela eclosão do terrorismo no Nordeste de Angola (Março de 1961)» (pp. 138 e 141). 
Como seria de esperar, o aumento do crescimento urbano explosivo foi acompanhado pelo aumento da complexidade dos problemas urbanos. Entre esses problemas são, justamente, os das migrações no interior da cidade, devido a alguns aspectos da rede de circulação, por falta de outros meios melhores e o aumento da distância entre os locais de trabalho e de residência (os problemas de circulação nesta cidade não parecem ser de hoje!). Não obstante isso, no conjunto dos variados problemas de Luanda, a situação dos «musseques» é, sem dúvida, o de maior gravidade e de difícil solução. São periferias de miséria económica e social, tal como existem nas Américas, Ásia e até mesmo na Europa.

No dizer do professor, os «musseques» de Luanda (os antigos «musseques», entenda-se), quase nasceram com a cidade; primeiro sob a forma de quintais onde os traficantes de escravos acumulavam as suas «peças» para exportação; depois sob a forma de aglomerados de cubatas localizados nos Coqueiros, no Bungo, nas Ingombotas ou nas Maiangas, habitados por africanos, escravos e libertos. A medida que a cidade se foi urbanizando com a construção de prédios e pela abertura de vias de comunicação, os «musseques» foram sendo expedidos para zonas cada vez mais distantes e de menor interesse.

Para o Professor Ilídio do Amaral, os «musseques» são «um caleidoscópio complicado, de facetas multiformes». Nele habitam os imigrantes do mundo rural, os imigrantes brancos de capacidade financeira diminuta, dos sem emprego permanente e dos desempregados e, até mesmo, de pequenos comerciantes e industriais. Ainda de acordo com o professor, «do professo de aculturação, que se desenvolve dos contactos múltiplos dos diferentes grupos, resultam aspectos que são peculiares aos "musseques"», tais como:

- Duplicidade de vida social, traduzida pelas diferenças de compor806 tamento de um mesmo indivíduo na cidade e no «musseque»;

- Sincretismo religioso, pela coexistência de cultos europeus e africanos;

- Formas de poligamia, particularmente entre a população africana menos urbanizada;

- A prostituição das mulheres africanas e a multiplicação de filhos de «pai incógnito»;

- Vadiagem dos homens; 
- Delinquência e outras ambivalências de atitudes que contribuem para a marginalização cultural dessas áreas;

- Multiplicação de certos tipos de «pequenos comércios», muitos deles clandestinos, onde muitas vezes se originam rixas de sábados a noite;

- Habitações não condignas.

Além desses aspectos críticos, outros mais pertinentes, se poderiam citar, dentre os quais a falta de mecanismos adequados de financiamento, de coordenação entre os programas habitacionais e os de estabelecimento de indústrias; de acessibilidade às escolas; de localização do comércio e dos serviços, enfim, ausência de organização espacial em comunidades, nas quais possa ser respeitada a evolução da vida familiar.

Finalmente, espero que tenhamos aprendido um pouco mais sobre Geografia Urbana, Geodemografia e História de Luanda, que muito sistematicamente nos foi revelada nesta obra excepcional pelo Professor Catedrático Ilídio de Melo Peres do Amaral, ou simplesmente, Ilídio do Amaral.

\section{Luiekakio Afonso}

(cf. supra, pp. 721-722) 